\title{
Climate Change: Climate Literacy and Response among USM Students
}

\author{
Wan Nur Syamilah Wan Ali ${ }^{1}$, Nasuha Lee Abdullah ${ }^{2}$ \\ ${ }^{1,2}$ Universiti Sains Malaysia \\ wansyamilah07@student.usm.my ${ }^{1}$,nasuha@usm.my²
}

Article History: Received: 10 November 2020; Revised: 12 January 2021; Accepted: 27 January 2021; Published online: 05 April 2021

\begin{abstract}
Climate change is a serious issue that not only affects Malaysia but also worldwide. Previous studies found that climate literacy may have a significant relationship with climate response while the level of education does not affect climate literacy. Thus, this study was conducted to gauge the level of climate literacy as well as their responses for Universiti Sains Malaysia (USM) students. A mobile climate application named SmaCli is proposed at the end of this study to address the issue of negative response towards climate change. The featuresof SmaCli are based on responses solicited from the questionnaire and the aim is to enhance climate literacy and encourage positive responses. However, for this paper, the prototype of the application is not included. A total of 196 responses were collected which consists of postgraduate and undergraduate students. The study found that $66 \%$ of the respondents have high literacy on climate change, level of education has no significant relationship with climate literacy level, mitigation act (climate response) showed a significant relationship with climate literacy level, and adaptation act (climate response) has no significant relationship with climate literacy. Hence, a concerted effort is still needed to improve climate literacy levels to ensure a positive climate response.
\end{abstract}

Keywords: Climate Change, Climate Literacy, Climate Response

\section{Introduction}

Climate change involves many dimensions as it happened due to human daily necessity activities (Boon, 2010), which mainly resulted from excessive greenhouse gases emission. It is reported by the Intergovernmental Panel on Climate Change (IPCC) in 2007 that the emission increased by $70 \%$ between 1970 and 2004 resulting from human activities that lead to the rise of new diseases, viruses and pest which then sparked new problems in the ecosystem (Kwon et al., 2019). In stressing the urgency of combating climate change and its issues, United Nation General Assembly in September 2015 set 17 goals, Sustainable Development Goals (SDG), that to be achieved by 2030, with the 13th of them being Climate Action ("Climate Action: Why it matters?", 2016).

Climate action can be defined as efforts that could be taken in coping through climate change by reducing greenhouse gas emissions as well as strengthening human adaptiveness to the impacts. This study which focused on the third objective of SDG 13, "Improve awareness and capacity on climate change mitigation, adaptation, impact reduction and early warning" involved elements of climate response and climate literacy. Climate response consisted of two mechanisms; mitigation and adaptation. Generally, mitigation was an effort that can be taken in reducing climate change while adaptation was an effort in adjusting to these changes. In nurturing positive response to climate change, improving literacy on climate change is a must (Beck et al., 2013). Climate literacy brings the meaning of understanding the climate, how we can influence it, and how it influences us. Zalina et al. (2015) stated that in changing behavior towards positive response on this matter, adequate knowledge on climate change and its impact are crucial. A study done by Bedford (2015) concluded that climate literacy of third education level students (bachelor and above) found to be low and it became one of the barriers in better response towards climate change (Stevenson, 2014). Without adequate climate literacy, individuals, as well as organizations, will be facing difficulties in making appropriate responses towards the matter. In addition to that, Beck et al. (2013) and Sinatra et al. (2012) found that climate literacy had a significant relation to climate response. When humans reduce their vulnerability in the act of mitigating and adapting towards climate change, the severity of climate change as well as its impacts can be lessened (Stacy, 2016).

Boon (2010) conducted a study to ascertain pre-service teachers on their understanding and knowledge about climate change issues compared to secondary students. From the study, it was found that there is a similarity between the two groups. Both of the groups show low literacy in climate change. Bedford (2015) on the other hand did a study on United States' students in determining their level of concern on anthropogenic global warming where he concluded that overall levels of climate literacy for primarily undergraduate students were low. Capstick et al. (2015) ran a study on finding perception of climate change throughout the public which found that public opinion differs across nations. This was resulted by media coverage, loss of interest among the public about the issue, collective denial, and political influences. 
Another study was done by Zhao et al. (2018) focusing on determining whether it is best to use single or joint adaptation and mitigation response in combating climate change. From the study, it was found that it is best to integrate both mitigation and adaptation. In addition to that, the study also suggested two mechanisms in joining both responses which were constructing and improving the monitoring and evaluation systems, as well as combining mitigation and adaptation measures at regional and departmental levels.

U.S. Department of Health and Human Services (2019) stated that low health literacy might lead to poor health response. Taking that relationship, an increase in climate literacy may result in a better response toward climate change. Where mHealth application introduced to help in promoting lifestyle disease prevention (Moi et al., 2017), an app that based on increasing climate literacy toward users may result in better response toward climate change in daily life among Malaysians. With this focus, a mobile-based application to increase the literacy of the public upon climate change that will help them in better response towards climate change will be proposed at the end of this study. Moreover, Dietz et al. (2009) stated that improving the literacy level of the public can support the adoption of positive behavior of climate response. Thus, this study was conducted with two main objectives which were to explore the relationship between education level towards climate literacy among USM students, as well as to know the relation between literacy level and their response toward climate change. These results at the end will be used in proposing a mobile-based climate application that would cater to the problems.

\section{Materials and Methods}

The research was conducted by distributing questionnaires to targeted respondents.

\subsection{Research Instrument}

The self-administered questionnaire for this research was adapted and adopted from studies done by previous researchers. The questionnaire was divided into four sections which were demographic data, climate literacy, climate response, and preference in a mobile application. Demographic data questions were constructed with a total of 5 questions. Climate literacy questions were adopted from Nasir et al. (2018), Anyanwu et al. (2015), Lopez et al. (2019), Hussain et al. (2019), Boon (2010), and Bedford (2015) with a total of 15 questions. The climate response section consisted of 11 questions, with six were for mitigation while five questions for the adaptation part. Climate response questions were adopted from Knowledge Attitude and Practice survey (KAP) on Climate Change (2016), Lopez et al. (2019), Ghani et al. (2019) and Anyanwu et al. (2015). Whereas, preferences in the mobile application were adapted from Moi et al. (2017) which consisted of five questions.

\subsection{Score}

For climate literacy, scores obtained by respondents were divided into A, B, C, D, E, and F as introduced by Leiserowitz and Smith's (2010) grading score. The score of 90-100 percent were graded as A, 80-89 percent as B, 70-79 percent as C, 60-69 percent as D, and 59 percent or lower as F. For this study, as grade A to D is considered as pass while $\mathrm{F}$ as a fail, respondents who scored between $\mathrm{A}$ and $\mathrm{D}$ are classified as having high literacy level while those who scored $\mathrm{F}$ are classified as low literacy level.

For climate response, the higher agreement towards climate facts gives a bigger point to respondents and vice versa, for the point ranged between five and one. The adaptation response consisted of five questions with an accumulation of 25 points for maximum points while the lowest was five. Meanwhile, the mitigation act consisted of six questions with maximum points of 30 while the lowest was six. Caguimbal, Delacion, \& Medina (2013) divided the respondent with $75 \%$ to be in high while the rest as the low response. Thus, for this study, a minimum score of 22 ( $0.75 \times 30$ points) is classified as having a positive mitigation act while the score of 19 $(0.75 \mathrm{X} 25)$ is set for a positive adaptation act.

\subsection{Data collection}

With a total of 36 questions, the questionnaire was blasted through social media which were Facebook, WhatsApp, and Telegram to collect responses. The study was done via a cross-sectional survey method using a convenient sampling technique where the respondents selected due to their convenient proximity. The respondents were USM undergraduate and postgraduate students; postgraduate students represent higher education levels while undergraduate students represent lower education level groups. The time frame of accepting feedback and response to the survey was two weeks. Data collected from the survey were then analyzed using SPSS version 24 . Univariate and chi-square analysis techniques were used to analyze the data. 


\section{Results and Discussion}

The results and discussion of the study are presented in the following five subsections.

\subsection{Demographic data}

The total number of respondents who participated in the survey was 196. They consisted of mixed backgrounds with different schools of study and gender. Among 196 respondents, $30.6 \%$ were male $69.4 \%$ were female. Undergraduates consisted of $71.9 \%$ while $28.1 \%$ were postgraduate students.

\subsection{Climate literacy}

Overall, climate literacy as measured by the 15 questions was found to be high among respondents. Mean, median, and modal scores out of these questions were 8.7, 9, and 9 respectively. Using the scoring method as per section 2.2, the results showed $5.1 \%$ of the respondent scored A, 9.7\% scored B, $11.7 \%$ scored C, $39.8 \%$ scored $\mathrm{D}$, and $33.7 \%$ scored F. Hence, 130 which represented $66.3 \%$ of the respondent is found to have high literacy level while $33.7 \%$ of respondent have low literacy level.

Table 1. Climate literacy

\begin{tabular}{lll}
\hline Literacy level & Frequency & Percentage \\
\hline High & 130 & 66.3 \\
Low & 66 & 33.7 \\
\hline
\end{tabular}

From the finding, it can be seen that the majority of respondents have a high climate literacy level. However, a study by Bedford (2015) found that the climate literacy of third education level students (bachelor and above) was low. The findings might be different due to the nationality of the targeted respondent. As mentioned by Capstick et al. (2015), public opinion on climate change as well as differs across nations. It could also be due to respondents being aware that marks are given to every correct answer on climate literacy, with the nature of students wanting to score high, respondents may tendto 'google' for the right answer when responding to the questionnaire. Nevertheless, it is still a concern to discover that there are $33 \%$ of respondents who scored F.

\subsection{Climate response}

As mentioned previously, climate response consisted of mitigation and adaptation. It is classified into a positive response or negative response as mentioned in section 2.2.

Climate mitigation

Table 2 shows the mitigation level based on respondents' scores. $67.9 \%$ of respondents were found to have a negative mitigation level while $32.1 \%$ were found to have a positive mitigation level.

Table 2. Climate mitigation

\begin{tabular}{lll}
\hline Climate Mitigation level & Score & Percentage \\
\hline Negative & 133 & 67.9 \\
Positive & 63 & 32.1 \\
\hline
\end{tabular}

i. Climate adaptation

Table 3 shows the adaptation level based on respondents' scores. $69.4 \%$ of respondents were found to have a negative adaptation level while $30.6 \%$ were found to have a positive adaptation level.

Table 3. Climate Adaptation

\begin{tabular}{|c|c|c|c|}
\hline $\begin{array}{l}\text { Climate } \\
\text { Level }\end{array}$ & Adaptation & Score & Percentage \\
\hline Negative & & 136 & 69.4 \\
\hline Positive & & 60 & 30.6 \\
\hline
\end{tabular}

From the results, respondents showed negative responses towards climate change for both mitigation and adaptation. 


\subsection{Education level and climate literacy}

To analyze the relationship between education level and climate literacy, a chi-square test was conducted as shown in Table 4. It can be concluded that there is no statistically significant correlation between education level and climate literacy when the p-value was found to be 0.236 which is more than 0.05 .

Table 4.Cross Tabulation of Education Level and Climate Literacy

\begin{tabular}{l|lllllll}
\hline \multirow{2}{*}{ Education Level } & \multicolumn{6}{l}{ Climate Literacy } & \multicolumn{2}{l}{} & \multirow{2}{*}{ p-value } \\
\cline { 2 - 8 } & High & $\%$ & Low & $\%$ & Total & $\%$ & \\
\hline High & 40 & 72.7 & 15 & 27.3 & 55 & 100 & \multirow{2}{*}{0.236} \\
\hline Low & 90 & 63.8 & 51 & 36.2 & 141 & 100 & \\
\hline
\end{tabular}

The result concurs with the previous finding.

\subsection{Climate literacy and climate response}

The chi-square test results for climate literacy and climate mitigation showed there is a significant relationship between them. The p-value appeared to be 0.008 . which is smaller than 0.05 . Meanwhile, the pvalue for climate literacy and climate adaptation was found to be 0.359 which is more than 0.05 . Therefore, there is no statistically significant correlation between climate literacy level and climate adaptation. That means, higher or lower of one's literacy level does not significantly related to his/her climate adaptation. While responses in climate change consist of mitigation and adaptation, only mitigation shows a significant relationship towards climate literacy. This may be due to respondents of this study are students. Mitigation response is an act of reducing climate change, examples of mitigation acts include recycling, reducing the use of plastic, reducing carbon footprint, and so on. Therefore, students with some climate literacy are prone to adopt such activities. However, climate adaptation acts such as moving to higher ground to avoid flood or installing ventilation devices inside the house for better air circulation may not be the activities that a student could take. Thus, the insignificant relationship between literacy level and adaptation.

\subsection{Preference in mobile application}

$77 \%$ of the respondents have indicated their interest to use mobile applications for a better response to climate change. Table 5 shows the popular features selected by the respondents. The top three features are: latest information on climate change, ideas of reusing items, and suggestion of action to reduce waste.

Table 5.Preference in Mobile Application

\begin{tabular}{lll}
\hline Climate Adaptation Level & Frequency & Percentage \\
\hline Latest information on cc & 126 & 64.3 \\
Ideas of reuse of items & 105 & 53.6 \\
Suggestion of action to reduce waste & 101 & 51.5 \\
Weather forecast & 85 & 43.4 \\
$\begin{array}{l}\text { Nearest recycling centre } \\
\text { Location-based natural disaster } \\
\text { notification }\end{array}$ & 77 & 39.3 \\
\hline
\end{tabular}

These preferencesare then used to propose a mobile application named SmaCli aimed to improve climate literacy and response.

\section{Conclusion}

The results from this study concur with previous studies thata person with high education levelwillhavea high level of climate literacy. However, a high level of climate literacy can drive positive climate response as in taking mitigation action. Interestingly,this study found that even though climate literacy among USM students is high it did not directly transform into a positive climate response. Therefore, a concerted effort is still needed to continuously propagate climate literacy and encouragea positiveresponse.One of these efforts could be through the use of a mobile application named SmaCli. 


\section{Acknowledgment}

The authors would like to acknowledge the support from School of Computer Sciences, USM.

\section{References}

1. Anyanwu, R., Grange, L.L., \& Beets, P. 2015. Climate Change Science: The literacy of geography teachers in Western Cape Province, South Africa. South African Journal of Education, 35(3): 1-9.

2. Beck, A., Sinatra, G.M., and Lombardi, U.D. 2013. Leveraging higher education instructors in the climate literacy effort factors related to university faculty's propensity to teach climate change. The Int. Journal of Climate Change: Impacts and Response, 4: 4- 17

3. Bedford, D. 2015. Does climate literacy matter? a case study of U.S. students' level of concern about anthropogenic global warming. Journal of Geography, 115(5): 1-11

4. Boon, H. J. 2010. Climate change? Who knows? A comparison of secondary students and pre-service teachers. Australian Journal of Teacher Education, 35(1): 104-120.

5. Caguimbal, D., Delacion, D., Medina, A.G., Mendoza, M., Mendoza, R.J., Sanche, M. 2013. Level of awareness of the maritime students on the outcomes-based education. Educational Research International, 2(1): 7-12.

6. Capstick, S., Whithmarsh, L., Poortinga, W., Pidgeon, N. and Upham, P. 2015. International trends in public perception of climate change over the past quarter century.WIREs Climate Change, 6(1): 35-61.

7. Dietz, T., Gardner, G.T., Gilligan, J., Stern, P.C., and Vandenbergh, M.P. 2009. Household actions can provide a behavioral wedge to rapidly reduce US carbon emissions. Proceeding of the National Academy of Science of the United state of America, 106 (44): 18452- 18456

8. Hussain, A., Surendar, A., Clementking, A., Kanagarajan, S., Ilyashenko, L.K. (2019). Rock brittleness prediction through two optimization algorithms namely particle swarm optimization and imperialism competitive algorithm. Engineering with Computers, 35 (3), pp. 1027-1035.

9. Ghani, A.B.A., Mahat, N.I., Hussain, A., Mokhtar, S.S.M. (2019). Water sustainability in campus: A framework in optimizing social cost. International Journal of Recent Technology and Engineering, 8 (2 Special Issue 2), pp. 183-186.

10. Knowledge Attitude and Practice Study on Climate Change. Japan- Caribbean Climate Change Project September, 2016 Belize. Available at https://www.adaptationundp.org/sites/default/files/resources/knowledge_attitudes_and_practice_study_on_climate_change_in_ belize.pdf. [Accessed 27 September 2019]

11. Kwon, S., Kim, S., and Lee, J. 2019. Analyzing the determinants of individual action on climate change by specifying the Role of Six Values in South Korea. Sustainability 2019, 11(7): 1-24.

12. Leiserowitz, A., Maibach, E., Roser-Renouf, C. and Smith, N. 2010. Global Warming's Six Americas. Yale University and George Mason University. New Haven, CT: Yale Project on Climate Change.

13. Lopez, L.S., Hewitt, B.A. and Sharma, S. 2019. Reaching a breaking point: how is climate change influencing the timing of ice breakup in lakes across the northern hemisphere? Limnol. Oceanogr 9999, $1-11$.

14. Moi, W.Y., Nasuha, L.A., Rosnah, I. and Keikhosrokiani, P. 2017. Lifestyle disease prevention: Health literacy, health attitude and mHealth. 2017 International Conference on Research and Innovation in Information Systems (ICRIIS), Langkawi 2017, 1-6.

15. Nasir, N., Hanifah, M., Mohmadisa, H., Yazism, S., and Sayidatina, B. 2018. Verificaiton of the instrument of cimate literacy knowledge among feature teachers: Confirmatory Factor Analysis (CFA). International Journal Aademic Research in Progressive Education \& Development, 7(3): 27-39.

16. Sinatra, G.M., Kardash, C.M., Taasoobshirazi, G., and Lombardi, D. 2012. Promoting attitude change and expressed willingness to take action toward climate change in college students. Instructional Science, 40: 1-17.

17. Solomon, S., D. Qin, M. Manning, Z. Chen, M. 2007. Contribution of working group i to the fourth assessment report of the Intergovernmental Panel on Climate Change (IPCC). Summary for policymakers. Climate change 2007: The Physical Science Basis.

18. Stacy, A.A.H. (2016). Knowledge, Attitudes \& Practices Study on Climate Change Adaptation \& Mitigation in Guyana. United Nations Development Programme (UNDP).

19. Stevenson, H. (2014). Representing Green Radicalism: The limits of state-based representation in global climate governance. Review of International Studies. 40(1): 177-201.

20. U.S. Department of Health and Human Services. (n.d.). Health Literacy Basics [Fact Sheet]. Retrieved from https://health.gov/communication/literacy/quickguide/factsbasic.htm [Accessed 27 September 2019] 
21. United Nation (2016)“Climate Action: Why It Matters?” (Action letter:2016), https://www.un.org/sustainabledevelopment/wp-

content/uploads/2016/08/13_Why_it_Matters_Climate_Action_letter_size_1p.pdf [Accessed

27 September 2019]

22. Zalina, M.D., Norazizi, M., and Norzaida, A. 2015. Public knowledge of climate change: Malaysia's perspective. The 2nd International Conference on Human Capital and Knowledge Management.

23. Zhao, C., Yan, Y., Wang, C., Tang, M., Wu, G., Ding, D., and Song, Y. 2018. Adaptation and mitigation for combating climate change - from single to joint. Ecosystem Health and Sustainability, 4(4): 85-94. 